\title{
Assessment of groundwater vulnerability to anthropogenic pollution and seawater intrusion in a small tropical island using index-based methods
}

\begin{abstract}
In this work, the DRASTIC and GALDIT models were employed to determine the groundwater vulnerability to contamination from anthropogenic activities and seawater intrusion in Kapas Island. In addition, the work also utilized sensitivity analysis to evaluate the influence of each individual parameter used in developing the final models. Based on these effects and variation indices of the said parameters, new effective weights were determined and were used to create modified DRASTIC and GALDIT models. The final DRASTIC model classified the island into five vulnerability classes: no risk (110-140), low (140-160), moderate (160-180), high (180-200), and very high (>200), covering 4, 26, 59, 4, and $7 \%$ of the island, respectively. Likewise, for seawater intrusion, the modified GALDIT model delineates the island into four vulnerability classes: very low $(<90)$, low $(90-110)$, moderate (110-130), and high (>130) covering 39,33, 18, and $9 \%$ of the island, respectively. Both models show that the areas that are likely to be affected by anthropogenic pollution and seawater intrusion are within the alluvial deposit at the western part of the island. Pearson correlation was used to verify the reliability of the two models in predicting their respective contaminants. The correlation matrix showed a good relationship between DRASTIC model and nitrate $(\mathrm{r}=0.58)$. In a similar development, the correlation also reveals a very strong negative relationship between GALDIT model and seawater contaminant indicator (resistivity $\Omega \mathrm{m}$ ) values $(\mathrm{r}=-0.86)$ suggesting that the model predicts more than $86 \%$ of seawater intrusion. In order to facilitate management strategy, suitable areas for artificial recharge were identified through modeling. The result suggested some areas within the alluvial deposit at the western part of the island as suitable for artificial recharge. This work can serve as a guide for a full vulnerability assessment to anthropogenic pollution and seawater intrusion in small islands and will help policy maker and manager with understanding needed to ensure sustainability of the island's aquifer.
\end{abstract}

Keyword: DRASTIC; GALDIT; Vulnerability; Groundwater; Seawater intrusion; Artificial recharge; Small island 